Document downloaded from:

http://hdl.handle.net/10251/82099

This paper must be cited as:

Gimeno, J.; Bracho Leon, G.; Marti-Aldaravi, P.; Peraza, JE. (2016). Experimental study of the injection conditions influence over $n$-dodecane and diesel sprays with two ECN singlehole nozzles. Part I: Inert atmosphere. Energy Conversion and Management. 126:11461156. doi:10.1016/j.enconman.2016.07.077.

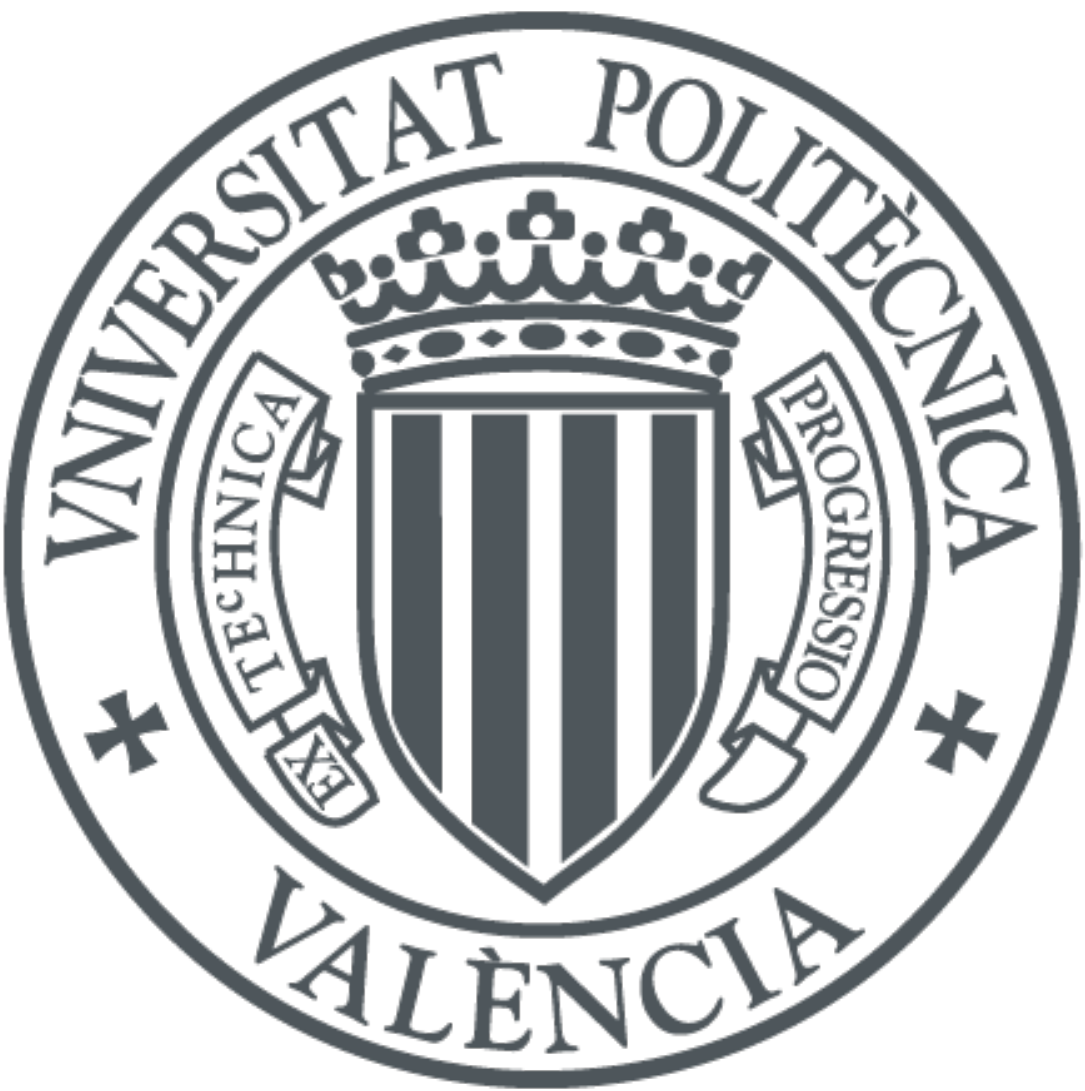

The final publication is available at

http://doi.org/10.1016/j.enconman.2016.07.077

Copyright Elsevier

Additional Information 


\title{
Experimental study of the injection conditions influence over n-dodecane and diesel sprays with two ECN single-hole nozzles Part I: Inert atmosphere
}

\author{
Jaime Gimeno $^{\mathrm{a}, *}$, Gabriela Bracho ${ }^{\mathrm{a}}$, Pedro Martí-Aldaravía ${ }^{\text {, Jesús E. Peraza }}{ }^{\mathrm{a}}$ \\ ${ }^{a}$ CMT - Motores Térmicos, Camino de Vera (s/n), Universitat Politècnica de València, Edificio 6D, 46022, Valencia, Spain.
}

\begin{abstract}
In this research, two Engine Combustion Network (ECN) mono-orifice nozzles, referred to as Spray C and Spray D respectively, were analyzed by performing visualization tests through Schlieren and Diffused Backlight Illumination (DBI) techniques under a wide range of ambient conditions in a non-reactive atmosphere. Spray C presents a straight nozzle designed with a sharp fillet in opposition to Spray D that has similar hydraulic properties, but with a convergent nozzle construction and a smoother corner. The experiments were carried out injecting two distinct fuels at different injection pressure ranges, from $50 \mathrm{MPa}$ to $150 \mathrm{MPa}$ with $\mathrm{n}$-dodecane and to $200 \mathrm{MPa}$ for diesel. The images were processed with Matlab home-built routines to calculate parameters as spray penetration, spreading angle, quasi-steady liquid length, as well as the spray penetration derivative respect to the square root of time, presented in this document as R-parameter. The results showed a clear influence of nozzle geometry in all measured parameters, due mainly to the nature of Spray $\mathrm{C}$ to cavitation, which increase the spreading angle and consequently a reduction in vapor penetration. On the other hand, fuel properties also affected spray penetration due to its dependency on viscous forces expressed in terms of the Reynolds number and its volatility in case of liquid length. This last parameter was calculated employing two processing methodologies, finding a good general agreement between them.
\end{abstract}

Keywords: Fuels, ECN nozzles, Tip penetration, Spray angle, Liquid length, Inert conditions

\section{Introduction}

Over last years, researchers have been keen on understanding the air-fuel mixing, evaporation and combustion processes in internal combustion engines, pushed by the interest in keep the pollutant emissions at levels that fulfill the ever more stringent environmental regulations, product of the increasing concern on climate change [1-3]. Computational Fluid Dynamic simulations represent a solution with tremendous potential, due to the great detail of information that they are able to provide and the possibility of avoiding the defiant problem of representing experimentally in-engine situations in controlled conditions [4]. However, experimental data of high reliability are essential to validating, setting boundary conditions and improving these computational models, since the current ones are not completely predictive [5].

A fundamental step forward in the comprehension of these phenomena was achieved with the definition and experimental characterization of specific features of the injection process such as tip penetration, spreading angle, liquid length, ignition delay, lift-off length, among others [6 7]. Many authors have performed spray visualization experiments employing facilities such as optically accessible engines [8] and test rig cells [9 10] in order to analyze these parameters. Two experimental approximations can be followed in this type of facilities to model the in-cylinder processes that occur in a diesel engine: carrying out the experiments in inert or reactive Cite as:

Corresponding author. E-mail address: jaigigar@mot.upv.es.

Gimeno, J., Bracho, G., Martí-Aldaraví, P., Peraza, J.E., "Experimental study of the injection conditions influence over n-dodecane and diesel sprays with two ECN single-hole nozzles. Part I: Inert atmosphere”, Energy Conversion and Management, (2016), Vol. 126, pp. 1146-1156. doi 10.1016/j.enconman.2016.07.077 


\begin{tabular}{|c|c|c|c|}
\hline \multicolumn{4}{|c|}{ Nomenclature } \\
\hline Acronyms & & $R e$ & Reynolds number \\
\hline ASOE & After start of energizing & $S$ & Penetration \\
\hline ASOI & After start of injection & $T$ & Temperature \\
\hline CMOS & Complementary metal-oxide-semiconductor & $t$ & Time \\
\hline $\mathrm{CPF}$ & Constant-pressure flow (facility) & & \\
\hline DBI & Diffused backlight illumination & \multicolumn{2}{|l|}{ Greek Symbols } \\
\hline $\mathrm{ECN}$ & Engine Combustion Network & $\Delta p$ & $p_{\text {rail }}-p_{a m b}$ \\
\hline EGR & Exhaust gases recirculation & $\nu$ & Kinetic viscosity \\
\hline LED & Light-emitting diod & $\rho$ & Density \\
\hline nDod & n-Dodecane (abbr. used in plot legends) & $\tau$ & Extinction \\
\hline PID & Proportional-integral-derivative controller & $\theta$ & Spreading angle of spray \\
\hline \multicolumn{2}{|l|}{ Variables } & \multicolumn{2}{|l|}{ Subscripts } \\
\hline C & Coefficients of discharge (defined by subscript) & 100 & Total distillation (temperature) \\
\hline$D$ & Diameter & $a$ & Area (coefficient) \\
\hline I & Image intensity & $a m b$ & Ambient condition \\
\hline$k$-factor & Conicity factor used in industry & $b g$ & In background \\
\hline$L L$ & Liquid length & $f$ & Fuel \\
\hline$\dot{M}$ & Spray momentum & $l$ & Liquid phase \\
\hline$p$ & Pressure & $o$ & Nozzle outlet \\
\hline \multirow[t]{3}{*}{$R$} & $R$-parameter & rail & In-rail, of injection (pressure) \\
\hline & & $\tau$ & Calculated by extinction method \\
\hline & & $v$ & Vapor phase - velocity (coefficient) \\
\hline
\end{tabular}

atmospheres. The reactive experiments physically and chemically resembles much more to the real situations in a combustion internal engine. However, inert tests represent a useful and simpler approach to determine boundary conditions, simulate without flame the fluid-thermodynamic processes in the biphasic spray, and to improve computational models [11].

Schlieren imaging and diffuse back-illumination (DBI) imaging are among the most employed optical techniques to measure spray features in vapor and liquid phases, respectively [12--14]. Many previous researches have been made in order to investigate the effects on spray liquid length and vapor phase development induced by engine parameters such as atmosphere conditions and injection pressure [15, 16, 6, 17], injector design [18], and fuel characteristics [6 19]. Parametric influence on spray angle has also been investigated in the past [7 20, 21], determining interesting aspects as its strong dependency on the ambient density and the fact that the appearance of cavitation on diesel injector nozzles can make the spray angle wider evidenced by visualization of transparent nozzles [20 22], laser sheet illumination[23] and X-rays [24]. In addition to this, some studies have confirmed the increment of turbulence at cavitating conditions, which promotes the jet break-up and enhances the mixing process [25].

The Engine Combustion Network (ECN) is a worldwide group created with the aim of sharing high quality data through the international collaboration of research centers, focusing efforts in the experimental and computational analysis of determined cases of study within the engine combustion knowledge field [26]. As part of the extension of the research coordinated by the ECN, single and multi-orifice injectors with nominally identical specifications (donated by Robert Bosch GmbH and Delphi Automotive Systems) are employed[27].

This investigation focuses on the understanding and characterization of the "Spray C" and "Spray D" ECN nozzles, whose internal geometries make them promote or avoid cavitation respectively, injecting two different chosen fuels: $\mathrm{n}$-dodecane and commercial diesel. In order to extensively cover both inert and reactive experimental approaches, the whole research was divided in two parts. This document presents the non-reactive part of the experiments analyzing vapor tip penetration, spreading angle and liquid length measures obtained with a constant-pressure flow facility (CPF) in a wide range of injection diesel-like conditions following the ECN guidelines. The employed optical setup allows both Schlieren and DBI high-speed to be recorded simultaneously. The second half of this research covers the analysis of those injectors, but in reactive conditions, measuring combustion parameters as well as ignition delat and lift-off length, and will be presented in a further document [28].

This manuscript has been divided into four sections. After the introduction, experimental hardware employed is described, along with details of the optical setups and the optical and image processing methodologies followed 
in this work. Results are presented and discussed next, for all measured parameters. At last, a section presents the conclusions obtained through the execution of this work.

\section{Materials and proceedings}

\subsection{Test rig and injection system}

A test chamber with optical accesses and capable of reproducing the in-cylinder thermodynamic conditions of a diesel engine at the time of injection was used to perform the experiments. This facility can be classified as a constant-pressure flow installation (CPF), according to the criteria used by Baert et al. [9]. Beside the fact that this test rig operates at high temperature and pressure conditions, up to $1000 \mathrm{~K}$ and 150 bar, nearly quiescent and steady thermodynamic conditions can be obtained within the chamber, capability which provides an important reduction in the time required to perform multiple repetitions of test matrices with wide range of conditions. This feature is unique compared with similar facilities in the world [9, 29, 18].

This test rig is basically composed of four sections: gas compressors, gas heaters, test vessel and control system. The high pressure gas, initially stored in reservoirs from the compressors, flows into the chamber through a $30 \mathrm{~kW}$ electrical heaters system placed upstream of it, increasing the gas temperature to the selected level. The vessel has a double wall configuration to enhance the temperature homogeneity within the chamber, where the internal thinner wall is surrounded with an insulating layer, in order to avoid heat losses towards the external shell, which has the structural function of supporting the inner gas pressure. The control system is a closed loop PID that adjusts both the pressure inside the vessel, and the power output of the heaters. Also, the rig is capable to being operated in open or closed circuit to test spray development either in a standard air atmosphere or with gas $/ \mathrm{N}_{2}$ mixtures with different $\mathrm{O}_{2}$ concentration, enabling to simulate the recirculation of exhaust gas (EGR) by decreasing the oxygen content of the charge. It is even possible to operate the rig in non-reacting conditions with $100 \% \mathrm{~N}_{2}$, as was done for these experiments. The chemical composition of the gas in the chamber is permanently measured by a lambda sensor and can be adjusted adding either air or nitrogen through a regulation system.

The experiments were performed with two target injectors of the Engine Combustion Network dataset. The Spray C nozzle is an axial single-hole Bosch 3-22 injector with a $k$-factor of 0 , whose design is oriented to be prone to cavitation. Moreover, the Spray D exhibits similar geometry, a rounded nozzle entrance and a convergent shape in order to avoid cavitation, conferring a $k$-factor of 1.5 . The geometrical and hydraulic properties of these nozzles have been characterized previously and can be found on the ECN web page [26]. The nozzles employed in this experience, according to the ECN coding reference, were the \#210003 (Spray C), which has an outlet diameter of $212 \mu \mathrm{m}$ and the \#209103 (Spray D), with a diameter of $192 \mu \mathrm{m}$. Those diameters were measured and reported in [30].

The setup of the injection system consisted in connecting the injector to a common rail with a high pressure line, and fit it in the vessel with a holder that has a continous ethylene glycol flow running in a parallel circuit, so the injector nozzle tip temperature could be mantained constant setting the fluid temperature [3]. Two fuels were used in the experiments, n-dodecane and diesel, whose properties are referred in Table 1 . The respective fuel of each test was provided to the injector by a volumetric pump driven by an electric motor, and the injection pressure was set by a PID system which controls a pressure regulator in the common rail. The experiments were performed in accordance with the conditions summarized in the test matrix shown in Table 2 .

Table 1: Fuel properties for n-dodecane and \#2 diesel [26].

\begin{tabular}{|c|c|c|c|}
\hline Fuel Property & n-Dodecane & Diesel & Units \\
\hline$T_{100}$ & 489 & 623 & K \\
\hline Cetane number & 87 & 46 & - \\
\hline Lower heat value & 44.17 & 42.975 & $\mathrm{MJ} / \mathrm{kg}$ \\
\hline Fuel density ${ }^{a}$ & 752.1 & 843 & $\mathrm{~kg} / \mathrm{m}^{3}$ \\
\hline Aromatics concent. & 0 & 27 & $\%$ (vol.) \\
\hline Kin. viscosity ${ }^{b}$ & 1.5 & 2.35 & $\mathrm{~mm}^{2} / \mathrm{s}$ \\
\hline Flash point & 356 & 346 & $\mathrm{~K}$ \\
\hline Plot legend reference ${ }^{c}$ & nDod & Diesel & - \\
\hline
\end{tabular}

${ }^{a}$ Value at $15^{\circ} \mathrm{C}$

${ }^{b}$ Value at $40^{\circ} \mathrm{C}$

${ }^{c}$ Name employed in plot legends due to spacing reasons
Table 2: Test conditions summary.

\begin{tabular}{lll}
\hline Parameter & Values & Units \\
\hline \hline Fuel $^{a}$ & n-Dodecane - Diesel & - \\
ECN injector label - code & C-210003 - D-209103 & - \\
Energizing time & 2.5 & $\mathrm{~ms}$ \\
Tip temperature & 363 & $\mathrm{~K}$ \\
Oxygen perc. $\left(O_{2} \%\right)$ & 0 (inert conditions) & $\%($ vol. $)$ \\
Gas temperature $\left(T_{a m b}\right)^{a}$ & $700-800-900$ & $\mathrm{~K}$ \\
Gas density $\left(\rho_{a m b}\right)^{a}$ & $7.6-15.2-22.8-35$ & $\mathrm{~kg} / \mathrm{m}^{3}$ \\
Injection pressure $\left(p_{\text {rail }}\right)$ & $500-1000-1500-2000^{b}$ & $\mathrm{bar}$ \\
\hline${ }^{a}$ Not all Fuel - $T_{a m b}-\rho_{a m b}$ possible combinations were & \\
performed. & & \\
${ }^{b}$ Only for diesel tests. & & \\
\hline
\end{tabular}




\subsection{Optical techniques and setups}

\subsubsection{Diffuse back-illumination imaging}

Diffuse back-illumination imaging (DBI) is one of the standard measure techniques applied by the ECN for liquid penetration [26]. It consists on the determination of the shape of the spray liquid phase based on the silhouette obtained by the obstruction of a beam of diffuse light with the jet at inert conditions. This technique have been used by several researchers to estimate the liquid length in quasi-stable state $(L L)$ [13, 14] and the transient liquid penetration $\left(S_{l}\right)$ [14, 31] for diverse atmosphere conditions combinations.

The setup utilized for this method is represented in Fig. 1 with its light main trajectory. The light beam is produced by a fast LED and goes through a diffuser which homogenizes and smooths the background of the spray image, and then reaches a fresnel lens to magnify the light intensity. After that, the light goes to a beam splitter that reflects perpendicularly part of it towards the spray. At last, the light travels to another beam splitter and is finally directed to a high-speed Photron SA5 camera that record the fuel injection. The LED pulse duration has been set at $57 \mathrm{~ns}$ as it is indicated along with other specifications of the system in Table 3

Table 3: Details of the optical setup for the employed techniques.

\begin{tabular}{lll}
\hline & $\begin{array}{l}\text { Diffused back- } \\
\text { illumination }\end{array}$ & $\begin{array}{l}\text { Schlieren } \\
\text { visualization }\end{array}$ \\
\hline \hline Camera & Photron SA5 & Photron SA-X2 \\
Sensor type & CMOS & CMOS \\
Lens diameter & $100 \mathrm{~mm}$ & $100 \mathrm{~mm}$ \\
LED pulse duration & $57 \mathrm{~ns}$ & - \\
Diaphragm gap & - & $4 \mathrm{~mm}$ \\
Filter range & - & $\leq 600 \mathrm{~nm}$ \\
Frame rate & $46.5 \mathrm{kfps}$ & $60 \mathrm{kfps}$ \\
Resolution & $256 \times 488$ & $256 \times 584$ \\
Shutter time & $1.01 \mu \mathrm{s}$ & $1.25 \mu \mathrm{s}$ \\
Pixel-mm & 7.00 & 5.88 \\
Repetitions & 8 & 8 \\
\hline
\end{tabular}

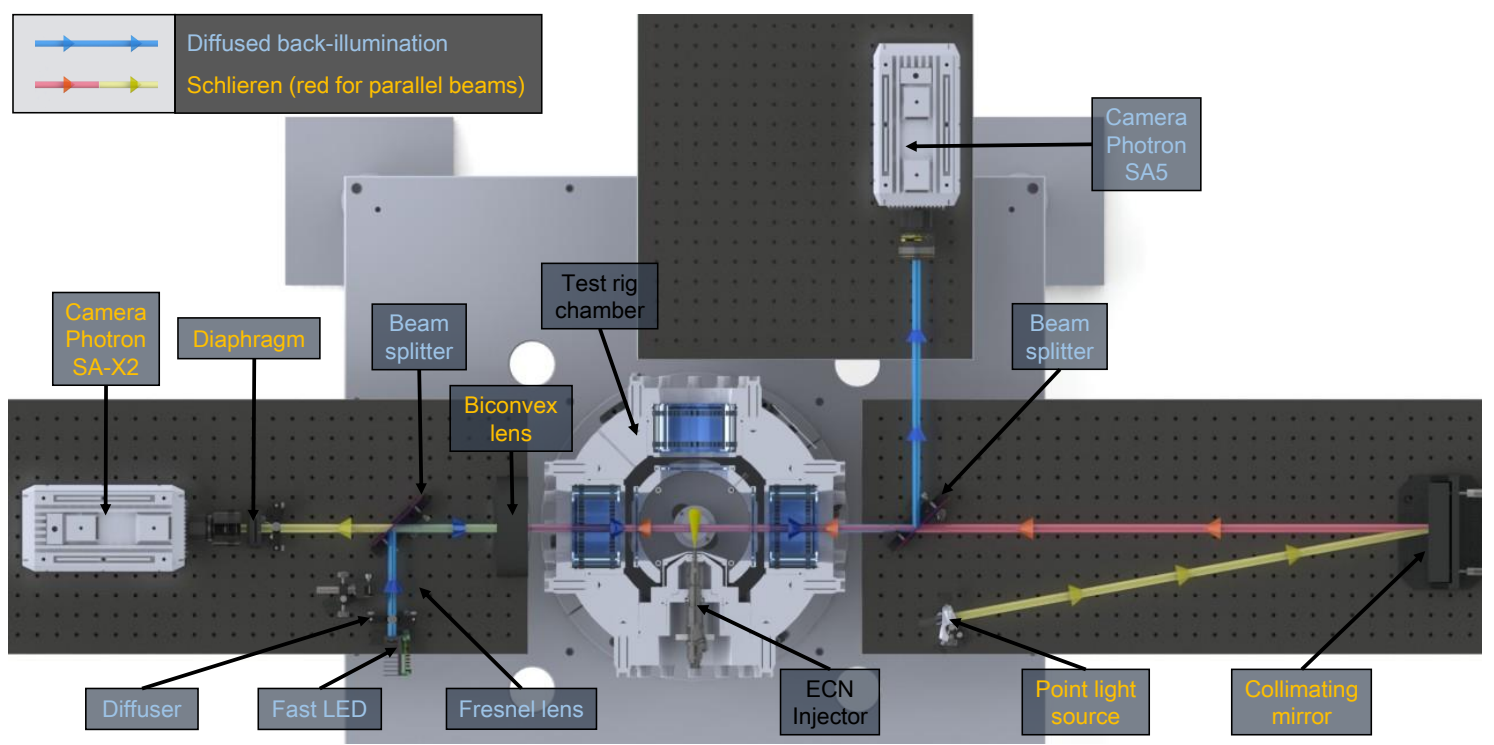

Fig. 1: Optical setup used. The main path of the light from its source to its respective camera along with the legend letters of the elements required for each technique are represented with colors. 


\subsubsection{Schlieren visualization}

Schlieren imaging technique is based on the fact that light rays are deflected as a consequence of them trespassing through a medium with density changes[32]. In this employment of the technique, a beam of parallel rays travels through the section where the fuel is injected. Filtering or discarding some of the deflected light due to the density gradients between the spray and the hot atmosphere inside the rig, let the Schlieren technique to detect the spray contour, allowing the extraction of information through the study in that boundary, such as vapor penetration $\left(S_{v}\right)$ and spray angle $\left(\theta_{v}\right)$.

To detect the spray boundaries, a conventional Schlieren single-pass setup was employed, whose scheme is shown in Fig. 1. This configuration is meticulously described by Pastor et al. [12]. A white-light $150 \mathrm{~W}$ halogen lamp with an incorporated diaphragm was placed at the focal length from of a collimating mirror to be used as the light source of the setup. The incident angle between the source and the mirror was minimized in order to reduce the beam straightening. After the mirror, the now parallel light beams are directed across the testing region obtaining, as a result of the deviation of light, information about the spray contour development inside the vessel. This deviated beam is collected by a $150 \mathrm{~mm}$ lens with a $450 \mathrm{~mm}$ focal distance, where a diaphragm (also known as plane of Fourier [12]) was located with a cut-off diameter of $4 \mathrm{~mm}$ just before the high-speed camera. Some details of the optical setup are presented in Table 3

\subsection{Image processing}

The image processing is one of the most decisive actions of the analysis of the data. Below, the different methods employed in the present work, are described:

\subsubsection{Time-varying penetrations and spreading angle}

Fast cameras were configured to utilize a time step between images of $21.5 \mu$ s for DBI and $16 \mu$ s for Schlieren recording, so penetrations of $0.2 \mathrm{~mm}$ on average could be detected. This slight time gap was possible thanks to the short light pulse emitted by the LED and to the advantage taken in terms of spatial resolution because of the nozzle being a single-hole axial nozzle. This allowed an accurate detection of the spray evolution in time and a good estimation of the SOI timing respect to the SOE time given by the trigger signal. Fig. 2 shows an example of the images obtained through the setup previously explained.

In order to obtain the macroscopic spray parameters of penetration in both liquid and vapor phases and the vapor angle from these images, were followed the steps described below, based on the post-processing methodology described in [17]:

- Background correction: In order to remove reflections and backdrop objects that could generate bad estimations of the contour, the background is taken as the image acquired before the start of injection, and is subtracted arithmetically to spray images. In Schlieren, this issue is critical because the acquired images are prone to present moving background structures, as a result of the temperature/density gradients in the testing ambient. Although these in-homogeneities cannot be considered steady, its movement is slow contrasted to spray velocities, so the structures can be considered steady between two consecutive images.

- Spray boundaries detection: Employing the approach employed by Siebers in [16], the contour was calculated binarizing the image. In Fig. 2 the Schlieren image series shows the typical spray vapor development behavior while it is penetrating across the chamber, where the major alterations of the spray happen at its tip and increasingly away from the injector. For DBI images, the first two images show the advance of the shadow that represents the liquid phase of the spray, while the following images present the appearance of lighter gray shades that correspond to the vapor phase. This occurs because part of the Schlieren light beam overlaps the DBI rays as Fig. 1 shows, so deviation of light as effect of the density gradients appears in DBI image in a lesser extent. To mitigate the noise effect related to this image interference and ensure a robust detection of the liquid phase silhouette, the threshold of the intensity determined as spray was kept elevated, but at the same time, in a low enough value to maximize sensitivity and avoid underestimations of the liquid contour. To maintain this equilibrium, the selected thresholds values correspond to $5 \%$ and $15 \%$ of the dynamic range for each image for Schlieren and DBI processing respectively.

- Contour analysis: Once the contour of the spray has been obtained, it is possible to calculate some of their geometrical features. Of these characteristics, those related to this work are: 

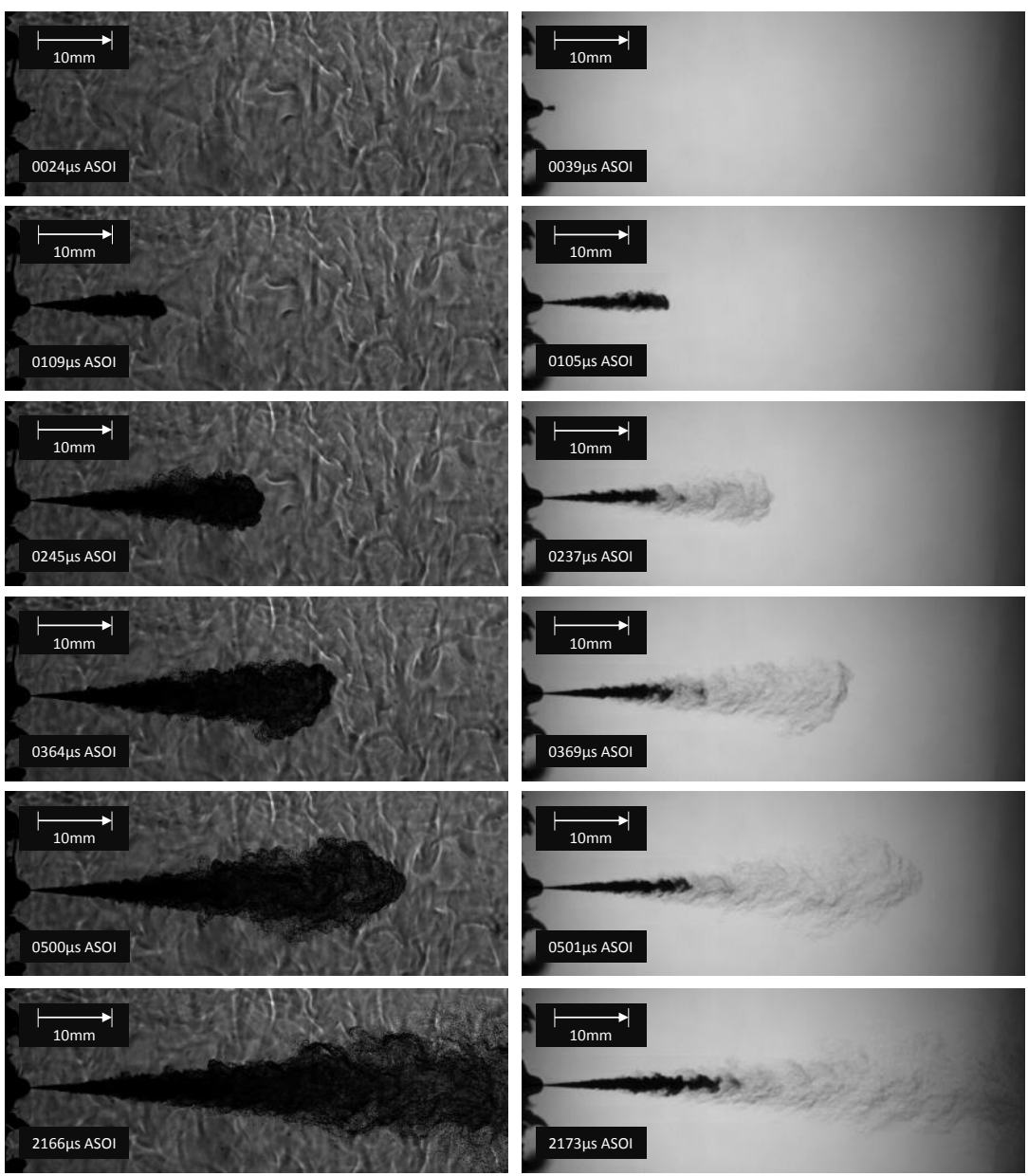

Fig. 2: Spray images series seen by Schlieren (left) and DBI method (right). Please observe that first pair of images from top to bottom represents the first images captured after the start of the injection. From second to fifth couple, pictures are separated by a constant temporary gap, while last couple was taken in an arbitrary time after vapor phase of the spray reaches the optical limit $($ Nozzle $=$ Spray D, Fuel $=\mathrm{n}-$ Dodecane, $T_{a m b}=900 \mathrm{~K}, \rho_{a m b}=15.2 \mathrm{~kg} / \mathrm{m}^{3}, p_{\text {rail }}=1500 \mathrm{bar}$ ).

- Penetrations $\left(S_{l}\right.$ and $\left.S_{v}\right)$ : Both the liquid and the vapor penetration, are calculated as the leading position of the spray contour in the images obtained by DBI or Schlieren imaging respectively.

- Vapor spreading angle $\left(\theta_{v}\right)$ : The spreading angle is obtained from Schlieren images detected contour. Once vapor penetration has been calculated, the spray angle is estimated as the angle of the trapezium whose bases are the segments inside the contour that coincide with distances of $12 \%$ and $50 \%$ of the instantaneous vapor penetration from the tip of the injector, as it is illustrated in Fig. 3 


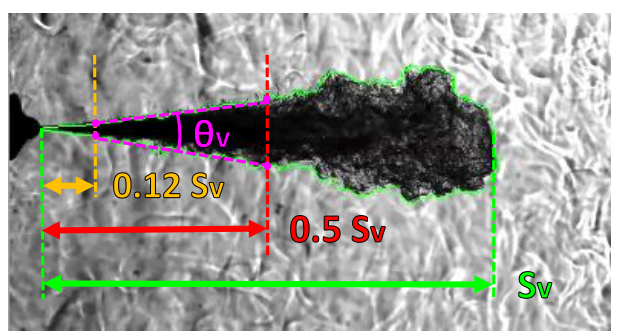

Fig. 3: Spreding spray angle calculation methodology example, through Schlieren imaging $\left(\right.$ Nozzle $=$ Spray $C$, Fuel $=\mathrm{n}-$ Dodecane, $T_{a m b}=$ $\left.800 \mathrm{~K}, \rho_{a m b}=15.2 \mathrm{~kg} / \mathrm{m}^{3}, p_{\text {rail }}=1000 \mathrm{bar}\right)$.

\subsection{2. $R$-parameter introduction}

From definitions given by injection theory of spray penetration, it is possible to obtain a new measurable parameter that describes the spray behavior. By the assumption of a conical shaped spray, some works present equations for the spray penetration in the Equation 1 form, from some ASOI time when the spray reaches the steady state in its evolution. Thereby, taking the spray angle and the momentum flux as constants from this stabilization point [33], the derivative of the spray penetration respect to the square root of time must be constant too. This derivative, mathematically illustrated in Equation 2 can be used as a novel parameter to characterize the external flow and compare metrics in different ambient conditions, as it has been employed by few past reseachers like Martí-Aldaraví in [34] under the name of $R$-parameter $(R)$. Fig. 4 represents with a test sample, the relationship between behavior of vapor penetration (left) and its $R$-parameter (right) and the effect of density in these variables. There it can be seen how the $R$ has a constant trend with time in its steady phase, with a little experimental variability.

$$
\begin{gathered}
S_{v}(t) \propto \dot{M}^{\frac{1}{4}} \cdot \rho_{a m b}^{-\frac{1}{4}} \cdot \tan ^{-\frac{1}{2}}\left(\frac{\theta_{v}}{2}\right) \cdot t^{\frac{1}{2}} \\
R=\frac{\partial S_{v}(t)}{\partial \sqrt{t}} \propto \dot{M}^{\frac{1}{4}} \cdot \rho_{a m b}^{-\frac{1}{4}} \cdot \tan ^{-\frac{1}{2}}\left(\frac{\theta_{v}}{2}\right)
\end{gathered}
$$

This new parameter $R$ is interesting to characterize injection phenomena because, being approximately constant, it can be represented in one single averaged value $\bar{R}$ for each test condition combination. R-parameter is independent of time for a fully developed and stabilized spray and can be correlated to thermo-dynamic and fluid-dynamics properties of the event, such as spray momentum flux or gas density [34]. Furthermore, a penetration value calculated at a determined time $t_{\text {calc }}$ depends on the way in which the spray develops with time from SOI to $t_{\text {calc }}$, while $R$ is not influenced by its previous values or the elapsed time, making it a parameter capable to describe by itself the penetration evolution.
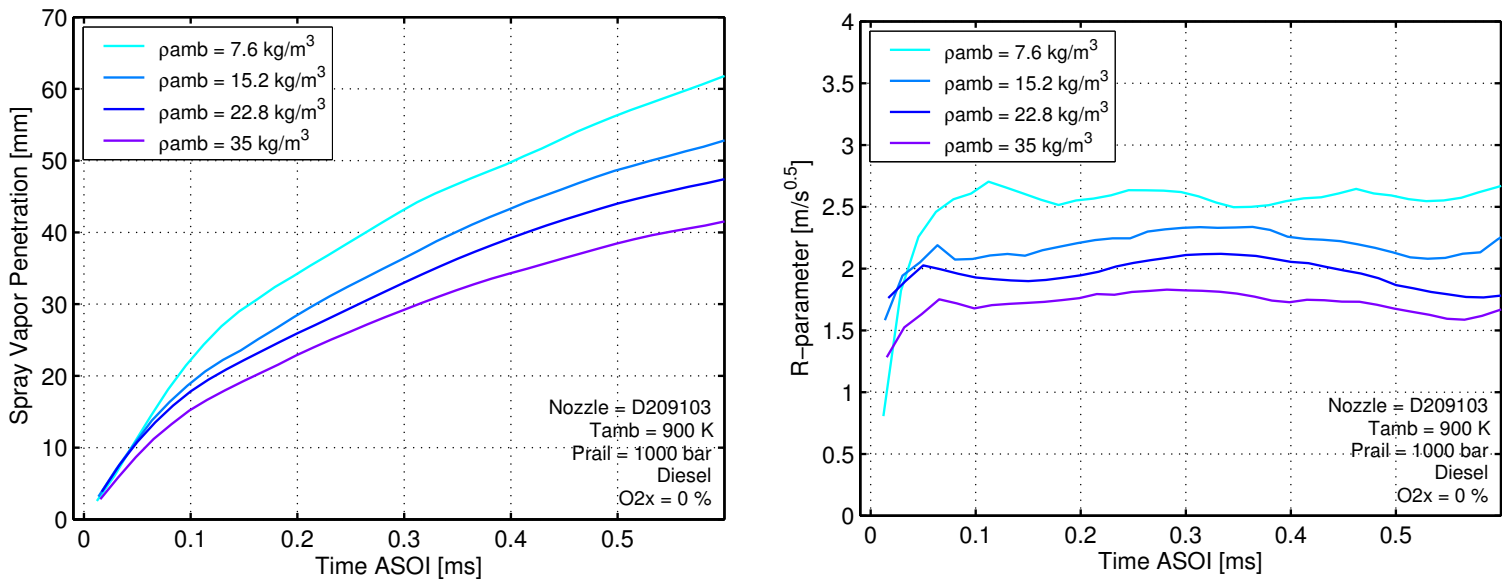

Fig. 4: Experimental example of an R-parameter calculation. Left: Vapor penetration comparison by densities of inert tests. Right: Rparameter measures for same conditions. $\left(\right.$ Nozzle $=$ Spray D, Fuel $=$ Diesel, $\left.T_{a m b}=900 \mathrm{~K}, p_{\text {rail }}=1000 \mathrm{bar}\right)$. 


\subsubsection{Liquid length}

Liquid length has been obtained from the light extinction profile of the DBI images, approach applied before in previous researches [26 13, 14]. The intensity of each pixel of the average image is related with the background intensity recorded before the start of the injection, through the Equation 3 where $I$ and $I_{b g}$ are the image intensity on each pixel and its corresponding incident intensity and $\tau$ is the optical thickness or extinction.

$$
\tau=-\ln \left(\frac{I}{I_{b g}}\right)
$$

After this step, it is possible to obtain the extinction of all the pixels of the spray axis for each injection repetition. This value along the axis usually describes a plateau profile that is characterized by a sharp decrease in the liquid length region [14]. The definition of liquid length considered has been called $L L_{\tau}$ in this work and is the same reported in [13], i.e. the intersection between the horizontal axis of an Extinction vs. Distance from Outlet plot and a linear fit of the decreasing slope of the extinction profile, as it is shown in Fig. 5.

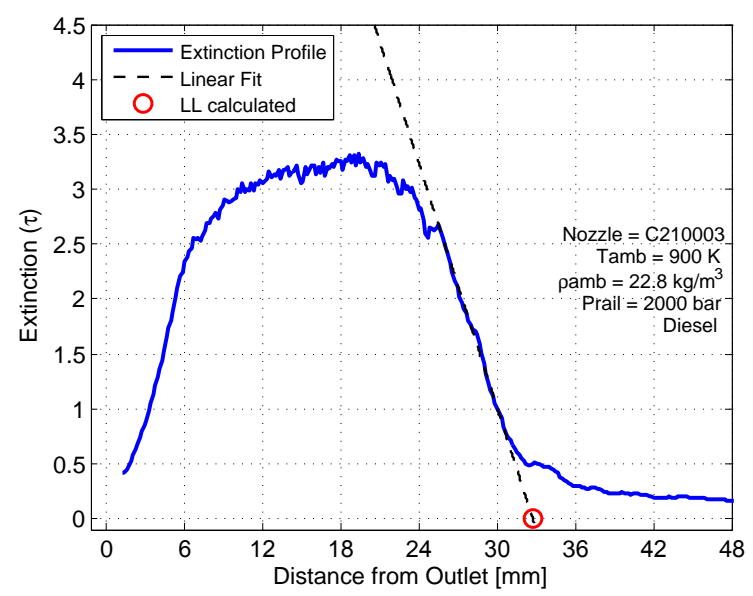

Fig. 5: Calculation of liquid length through the extinction profile obtained from the DBI images of an only injection event. The decreasing described by the profile is linearly fitted, and the value of this slope where it coincides with the X-axis is taken as the LL. (Nozzle $=$ Spray C, Fuel = Diesel, $T_{a m b}=900 \mathrm{~K}, \rho_{a m b}=22.8 \mathrm{~kg} / \mathrm{m}^{3}, p_{\text {rail }}=2000 \mathrm{bar}, \mathrm{O}_{2} \%=0 \%$ ).

\section{Results and discussion}

\subsection{Tip penetration}

Fig. 6shows the temporal evolution of the vapor phase tip penetration for inert tests that were performed with the Spray C as nozzle and diesel fuel. This injector and fuel configuration was arbitrarily selected to present the impact of ambient temperature, density and injection pressure in axial spray penetration and it presents similar patterns for another combinations. Fig. 6left plot demonstrates how strong is the effect of ambient density on the spray penetration on the very beginning of its development. Once the spray advances deeper into the vessel volume, this influence becomes more evident causing slower penetrations when the test rig is operated at higher densities. Similarly, it is also very noticeable in Fig. 6 right part that the higher injection pressure is, the faster tip penetration goes forward due to the higher momentum. Finally, it can be observed in both plots of Fig. 6 that gas temperature produces a negligible difference in vapor tip penetration, with a slight trend to accelerate the spray advancement with a decrease of temperature. 

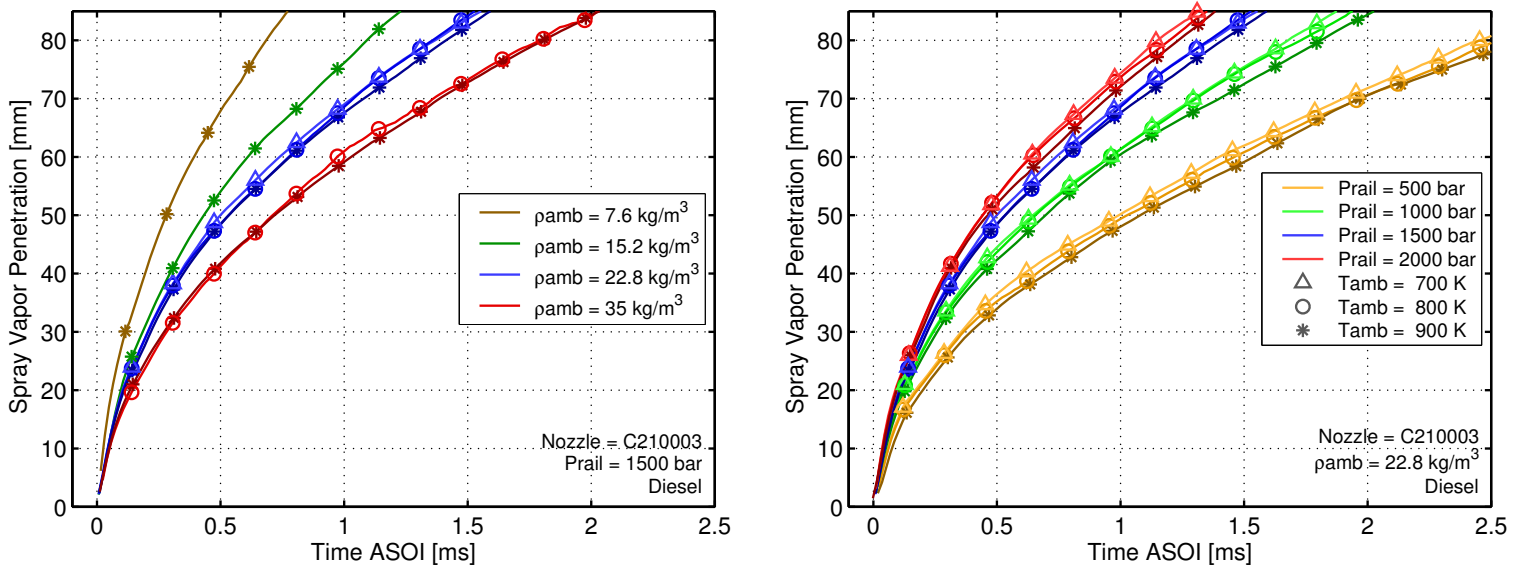

Fig. 6: Vapor tip penetration results for diesel tests with Spray $\mathrm{C}$ as nozzle at different temperatures. Left: Tip penetration at $p_{\text {rail }}=1500$ bar and different atmosphere densities. Right: Tip penetration at $\rho_{a m b}=22.8 \mathrm{~kg} / \mathrm{m}^{3}$ varying injection pressure. Color shades represent temperature variations.

Moreover, in Fig. 7 it can be appreciated how evaporation mechanisms make liquid penetration behaves in a different way than vapor penetration. At this time, n-dodecane and spray D where selected as fuel-nozzle combination. A similarity with vapor phase is that at lower densities the liquid penetration is faster as well as stabilizes at higher values. Two factors that likely contribute to that, as it is discussed in [15], are the faster breakup and mixing rates that are produced by higher densities, and the increment of the effective mixture temperature led by the higher amount of hot air entering into the liquid spray. Also, a rise in ambient temperature strongly accelerates liquid evaporation rate as a result of the intensification of the kinetic energy of the spray surface molecules, shortening therefore the liquid penetration. Nevertheless, now it is the injection pressure which does not seem to have a significant effect on the liquid penetration as seen in Fig. 7 right part, where nine different tests collapse to approximately three well differenced liquid penetration curves that are defined by the three different temperatures. Another consideration in the figure is that liquid penetration shows, always during the steady injection interval, a slight growth until certain time; a possible cause contemplated by another authors in [3 17] is that the fuel temperature is higher at the injection beginning because the injector tip is continuously in direct contact with the high temperature gases of the inner chamber ambient, while during the injection the fuel flows through the injector and the tip cools down, reducing nozzle and fuel average temperatures and consequently increasing the liquid length. This possibility is further supported by the fact that liquid penetration increment becomes smaller with time until reach a maximum value near the end of injection.
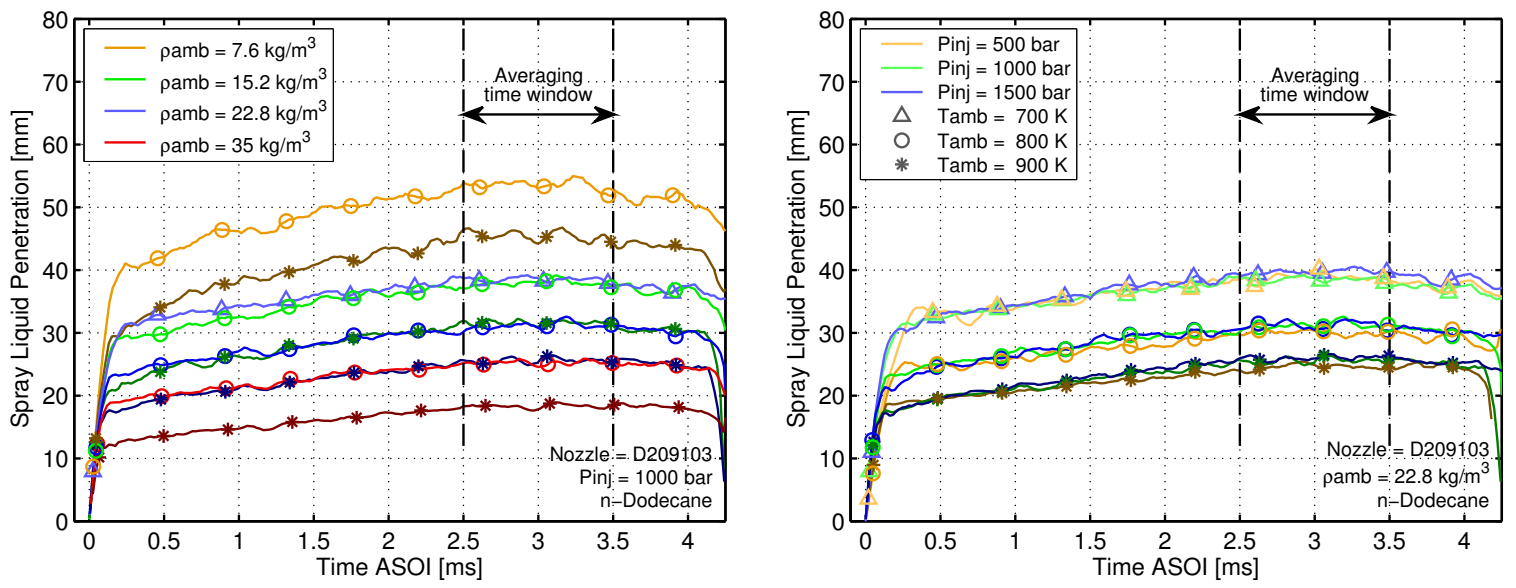

Fig. 7: Liquid penetration calculated for $\mathrm{n}$-dodecane tests with Spray D as nozzle at different temperatures. Left: Tip penetration at $p_{\text {rail }}=$ 1000 bar and different atmosphere densities. Right: Tip penetration at $\rho_{a m b}=22.8 \mathrm{~kg} / \mathrm{m}^{3}$ varying injection pressure. Color shades represent temperature variations.

Each curve in Fig. 6 and Fig. 7 represents the average result of the 8 repetitions for each condition, following 
a rolling-average algorithm with the same concept that a Savitzky-Golay digital filter. The algorithm is described in [35].

Regarding to the nozzle geometry and fuel variation influence on inert spray penetration, Fig. 8 shows certain behaviors. It is possible to appreciate significant differences in liquid phase penetration between fuels, reaching higher values for diesel. Nozzle geometry also has influence on liquid penetration, but not as important as fuel variation does. These dependences will be explained more extensively in the section corresponding to the liquid length analysis. Concerning vapor phase penetrations, for the injection conditions illustrated in Fig. 8 it can be seen how n-dodecane penetrates slightly faster employing the Spray D nozzle than the other three nozzle-fuel configurations, which seem quite similar. However, this is not entirely conclusive nor easy to analyze for only one or few combination of chamber ambient conditions and injection pressures, so that it would be interesting to study the penetration of vapor phase employing a parameter independent of time and more manageable to evaluate various operating conditions, as the before referred $R$-parameter.

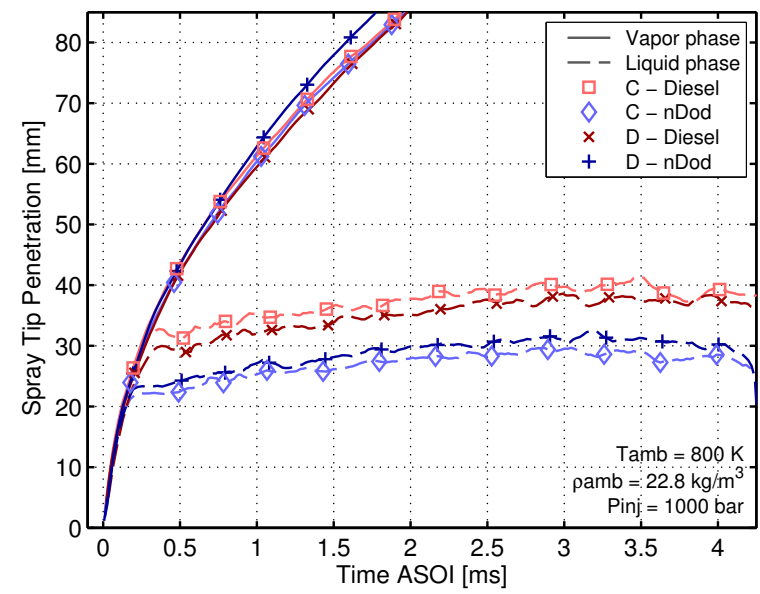

Fig. 8: Vapor and liquid spray penetration evolution with time for different nozzle-fuel combinations $\left(T_{a m b}=800 \mathrm{~K}, \rho_{a m b}=22.8 \mathrm{~kg} / \mathrm{m}^{3}, p_{\text {rail }}\right.$ $=1000$ bar .

\section{2. $R$-parameter}

As already mentioned, vapor tip penetration can be expressed in R-parameter terms, which could be an easier definition to compare its dependence on multiple conditions as it is done in Fig. 9 This plot shows how $\bar{R}$, whose meaning is equivalent or relative to the speed of propagation of the spray, is increasing with the injection pressure and that this effect tends to decrease as pressure is greater, which is expectable. This behavior and the effects of density and temperature variations on the atmosphere agree with the previous conclusions about vapor penetration, but also this figure reflects how these trends are common in all nozzle-fuel combinations.

In Fig. $9 \bar{R}$ is notably less affected by the nozzle geometry or the injected fuel than by injection pressure and ambient density. The last two, influence in a more strongly and clearly way than temperature changes. The clearest trend seen is that for Spray D, n-dodecane always penetrates faster than diesel. In case of the straight Spray C nozzle, diesel trends to have a higher R-parameter than n-dodecane, with lesser difference between values than Spray D. Naber and Siebers model for steady-developed spray penetration in [6] (Equation 44) will be used to discuss this phenomenon, as it includes internal flow parameters as $C_{a}, C_{v}$ and $D_{o}$, which are the area and velocity coefficients and the nozzle diameter respectively. In a convergent and rounded entrance nozzle as Spray D which is not prone to cavitation, it is expectable that $C_{a}$ does not vary considerably for different fuels. However, for same operation conditions $C_{v}$ increases with Reynolds number $R e$, which will be larger for $\mathrm{n}$-dodecane than diesel since $R e \propto \nu_{f}^{-1}$. This explains why penetration and R-parameter tends to be greater for $\mathrm{n}$-dodecane than for diesel in Spray D tests.

$$
S_{v}(t) \propto\left(2 \cdot C_{a}\right)^{\frac{1}{4}} \cdot C_{v}^{\frac{1}{2}} \cdot \tan ^{-\frac{1}{2}}\left(\frac{\theta_{v}}{2}\right) \cdot \rho_{a m b}^{-\frac{1}{4}} \cdot \Delta p^{\frac{1}{4}} \cdot D_{o}^{\frac{1}{2}} \cdot t^{\frac{1}{2}}
$$



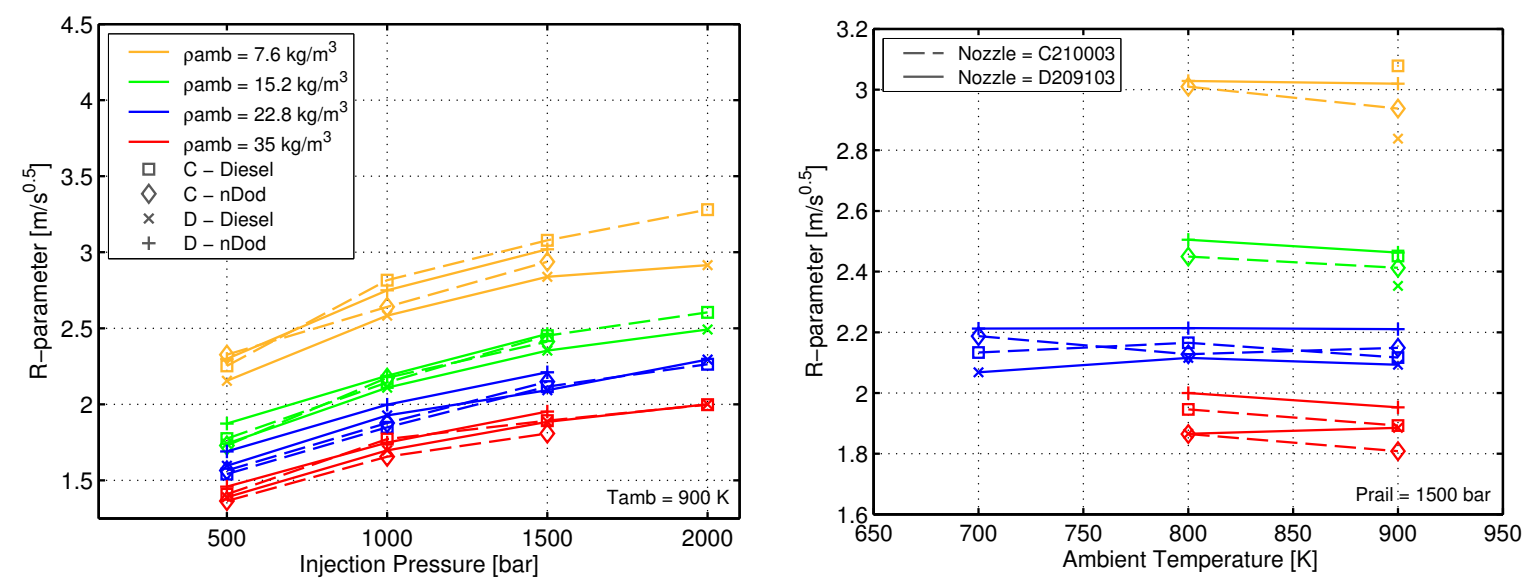

Fig. 9: $R$-parameter average of vapor penetration. Left: $\bar{R}$ in function of injection pressure at $T_{a m b}=900 \mathrm{~K}$. Right: $\bar{R}$ in function of gas temperature at $p_{\text {rail }}=1500$ bar.

On the other hand, in cavitating regimes as induced by geometrical features of Spray $\mathrm{C}$, Re significantly intensifies turbulence and cavitation [22]. Furthermore, cavitation is also strongly manifested for fuels with high vapor pressures (or low boiling temperatures $T_{100}$ [36]), which changes easily to gaseous phase. These two effects are stronger in $\mathrm{n}$-dodecane, and this enhance in the cavitation results in an increase of the spray spreading angle $\theta_{v}$ (as it can be appreciated in the next section) and a reduction in the effective diameter [37] (i.e. $C_{a}$ ) which, according to Equation 4 makes penetration lesser using n-dodecane than injecting diesel for Spray C. These behaviors of the flow coefficients in these same injectors are experimentally demonstrated in [30]. Finally, it is appreciable in Fig. 9 how these respective patterns are kept between fuels, but Spray $\mathrm{C}$ tends to have greater $R$-parameter and penetration than Spray D at low densities, and how the opposite occurs with high values of density, which can be explained by the $\theta_{v}$ rise with gas density [7] and how this reduces vapor penetration.

\subsection{Vapor spreading angle}

As previously stated, the spray angle and spray penetration are strongly related. In order to analyze how it is affected by the different variables controlled in this work, Fig. 10 shows the $\theta_{v}$ behavior with parametric changes in operating conditions. As occurs in previous studies [7, 19], in Fig. 11-left, it is possible to observe how ambient density causes an increment in $\theta_{v}$ as product of the enhancement in gas entrainment into the spray which is caused. Injection pressure and ambient temperature seem to have a lesser effect in spray angle. In case of $p_{\text {rail }}$, it tends to slightly arise the spray angle as Fig. 11-right shows, while it seems to increase more visibly with temperature. 

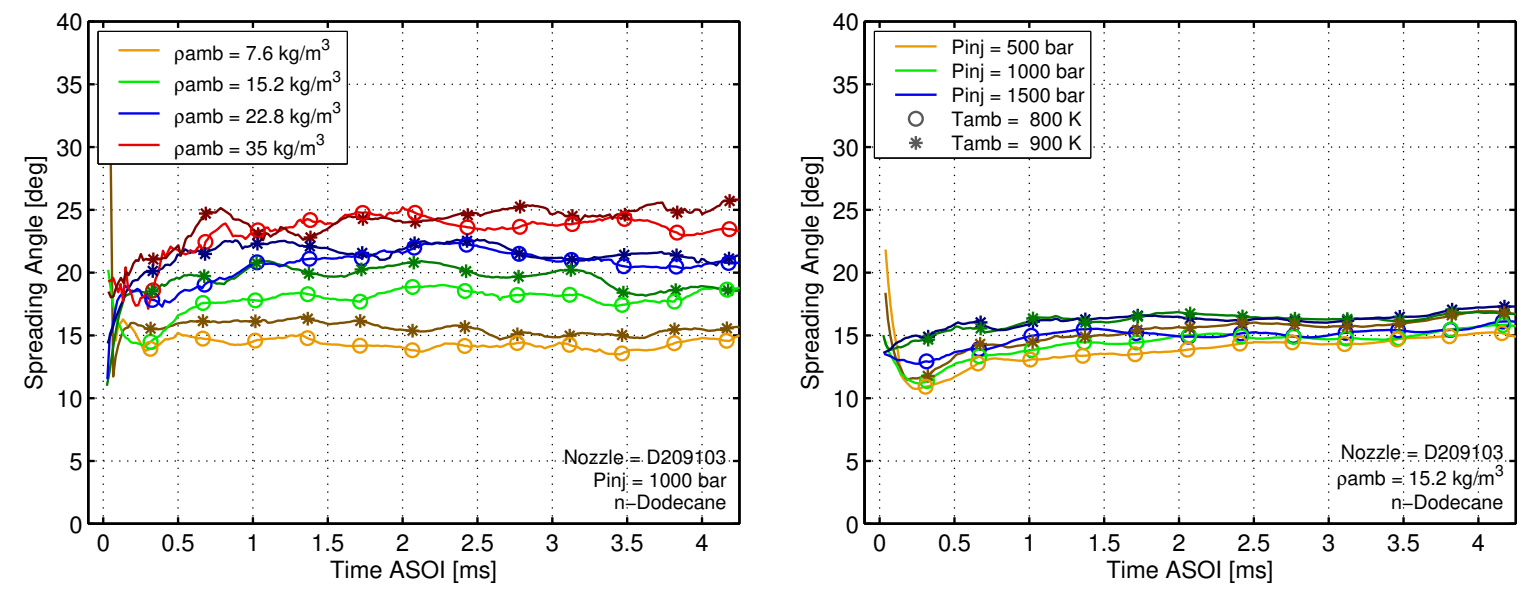

Fig. 10: Spreading spray vs. time at different operation conditions. Left: Spray angle at $p_{\text {rail }}=1000$ bar and different atmosphere temperature and densities. Right: Spray angle at $\rho_{a m b}=15.2 \mathrm{~kg} / \mathrm{m}^{3}$, varying injection pressure and temperature. Darker shades of the same base color represent higher temperatures.

As it can be seen in Fig. 10 the angle starts with transitoriness, and later it stabilizes. This allows to get an average spreading angle value from the steady phase of the spray, which is useful to analyze parametric variations, as it is done in Fig. 11. Reitz et. al in [19] described how the density and the viscosity of a fuel reduce the spreading angle of the spray, which explains that the general trend is that $\mathrm{n}$-dodecane disperses with a higher angle than diesel. However, an even more remarkable tendency is that angle is higher for Spray C than Spray $\mathrm{D}$, which can be explained by the cavitation induced in Spray C nozzle by its geometrical features. The effects of cavitation and injection pressure in spreading angle demonstrated to be quite consistent for the three higher densities tested. However, at $7.6 \mathrm{~kg} / \mathrm{m}^{3}$ can be seen some discrepancies or a weaker influence of those parameters.
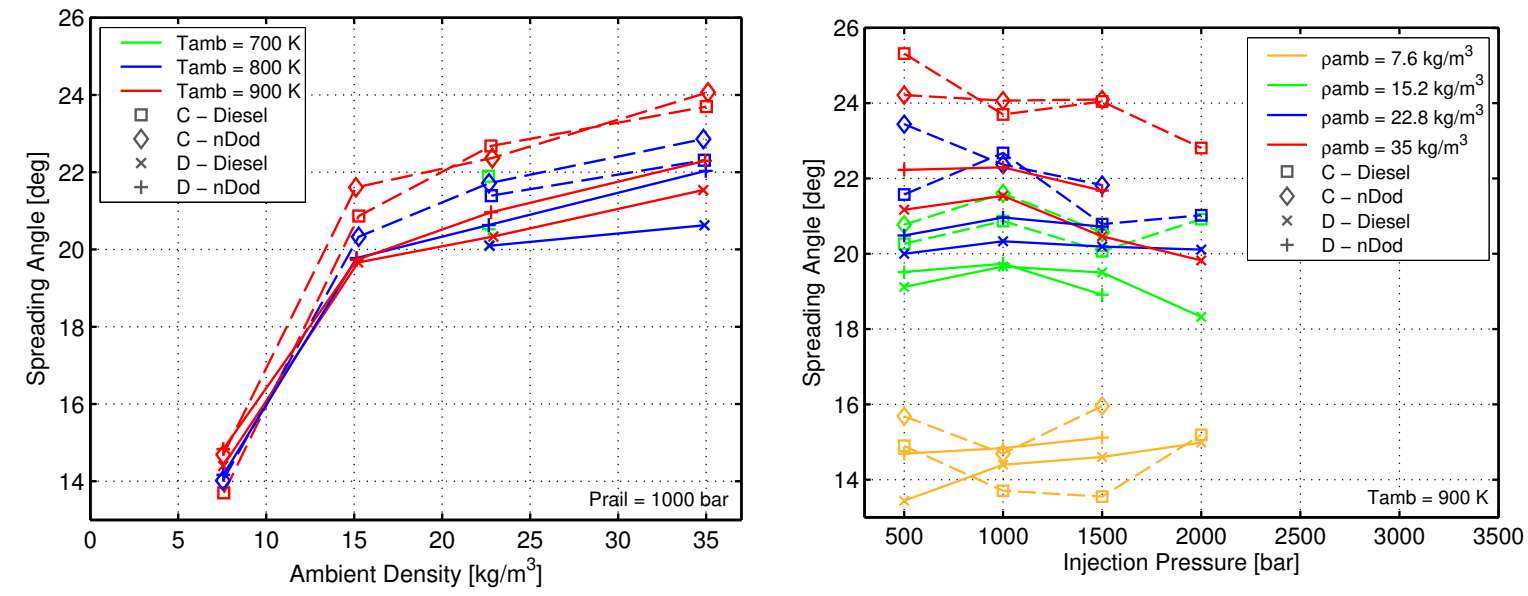

Fig. 11: Spreading spray angle variation with operation conditions. Left: Spray angle at $p_{\text {rail }}=1000$ bar and different atmosphere temperature and densities. Right: Spray angle at $T_{a m b}=900 \mathrm{~K}$ varying injection pressure and density. Dashed lines represent Spray C behavior while continous are for Spray D.

\subsection{Liquid length}

In order to understand the parametric variations effects in the spray liquid length, Fig. 12 left part shows the influence of ambient temperature and density (i.e. chamber back pressure), while Fig. 12 right plot presents injection pressure variations effect in $L L_{\tau}$. In accordance with the results discussed in the Tip penetration and $R$-parameter sections and illustrated in Fig. 7 it can be appreciated how the gas temperature and density have an important effect on liquid penetration and therefore, on liquid length, diminishing $L L_{\tau}$ with their rise as a product of the vaporization rate quickening in evaporative ambients and the aerodynamic interaction between spray and the atmosphere. However, this impact is decreasing as both the density and temperature are greater. 
Additionally, Fig. 12 allows to compare the liquid length in terms of nozzles, fuels and injection pressures. For Spray D, injection pressure seems to have essentially no strong influence on liquid length, while Spray C presents more noticeable deviations from 2 to up to $4 \mathrm{~mm}$ between injections of 500 and 2000 bar. This pattern in Spray C predominantly shows that $L L_{\tau}$ slightly increases with an augment of the injection pressure. Moreover, the nozzle geometry effect is analogous to the referred in Tip penetration and R-parameter sections. Cavitation makes discharge coefficients in Spray C quite susceptible to be reduced due to the higher $R e$ and turbulent regime of $n$-dodecane injection. However, the fuel volatility effect in liquid length is significantly stronger. The more volatile (lower $T_{100}$ ) the fuel, the shorter liquid length because its higher tendency to vaporize. Those combinated effects of nozzle geometry and fuel volatility make that the overall trend of $L L_{\tau}$ is C-Diesel $>$ D-Diesel $>\mathrm{D}$-nDod $>$ C-nDod, with a big difference between fuels.
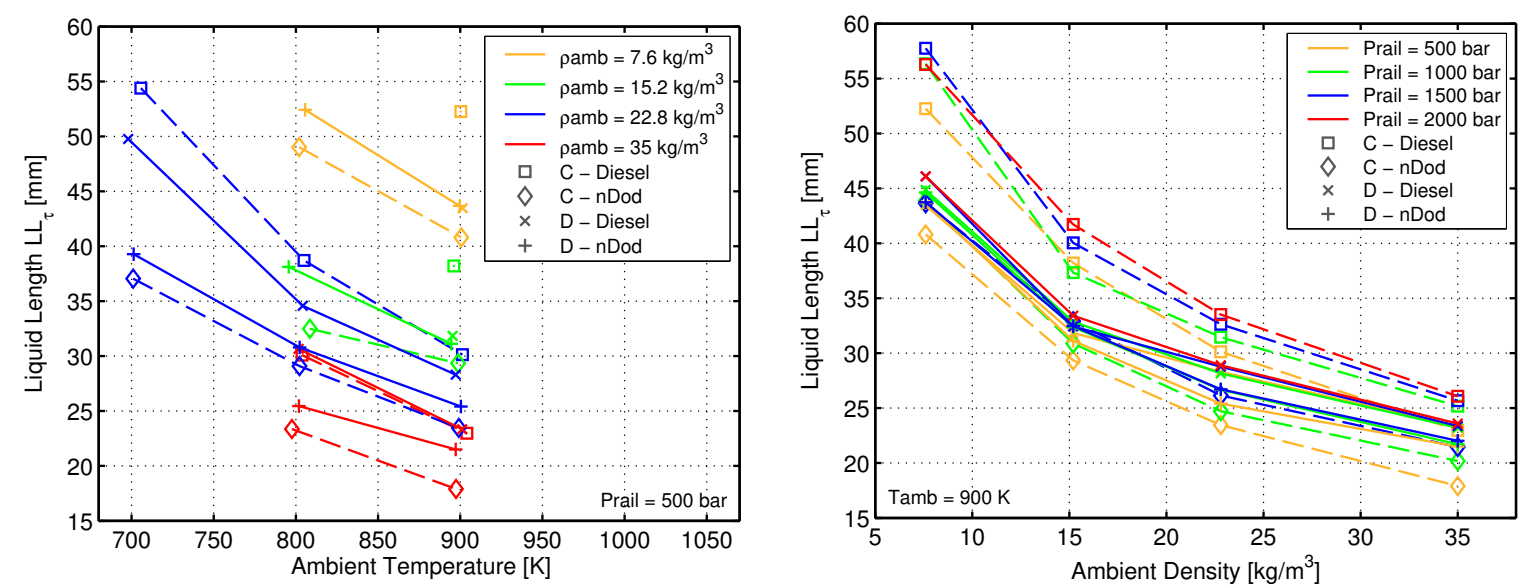

Fig. 12: Liquid length dependance of different operating conditions. Left: Gas temperature and density effects in liquid length at $p_{\text {rail }}=500$ bar. Right: Ambient density and injection pressure influence in $L L_{\tau}$ at $T_{a m b}=900 \mathrm{~K}$. Dashed lines represent Spray $\mathrm{C}$ behavior while continous are for Spray D.

Another way in which liquid length can be estimated, besides the method based in the calculation of the extinction $\tau$, is from the time-varying liquid penetration $S_{l}$. A representative value which can be compared with the $L L_{\tau}$ and to discuss both approach limitations, can be obtained by averaging the $S_{l}$ measured in a window of time. In order to be consistent with the extinction method, which works with the intensity recorded in the whole injection event, an interval in which liquid length is stabilized and reaches maximum values was selected for averaging; in this case, from 2.5 to $3.5 \mathrm{~ms}$ as it is indicated in Fig. 7 This mean value of liquid length has been defined as $\bar{S}_{l}$. Fig. 13 shows all liquid length values calculated by both methods without distinction different injection pressures, since it is the parameter with lesser influence in liquid length.

As Fig. 13 shows, both liquid length calculations are generally in very good agreement for all the condition range tested. The most important differences noticed happen at high temperatures and densities, where the liquid length has lower values. While the $L L_{\tau}$ comes from the average image relationship with an image before injection, the $\overline{S_{l}}$ takes the mean of the liquid time-varying penetrations. As mentioned, for these tests the liquid penetration tends to suffer variations with time. The interval taken as averaging time window was in which the fluctuations are the lowest. However, $\overline{S_{l}}$ calculation is susceptible of these undulations and, at lower values, they can represent a more important percentage of inaccuracy. On the other hand, the average image considers all the liquid length values reached during the whole injection, thus it is understandable that $S_{l}$ fluctuations make that $\overline{S_{l}}$ underestimates slightly the liquid length respect to $L L_{\tau}$.

\section{Conclusions}

Two ECN single-hole nozzle injectors, liable to cavitating and non-cavitating regimes, were tested using diesel and $n$-dodecane in a wide range of diesel-like injection conditions with the goal of measure spray macro-characteristics. Also, a novel definition referred to $R$-parameter, which represents the penetration derivative respect to the square root of time, was introduced and calculated for all test conditions. From the analysis of the results obtained from this experiments, the following considerations can be conclude: 


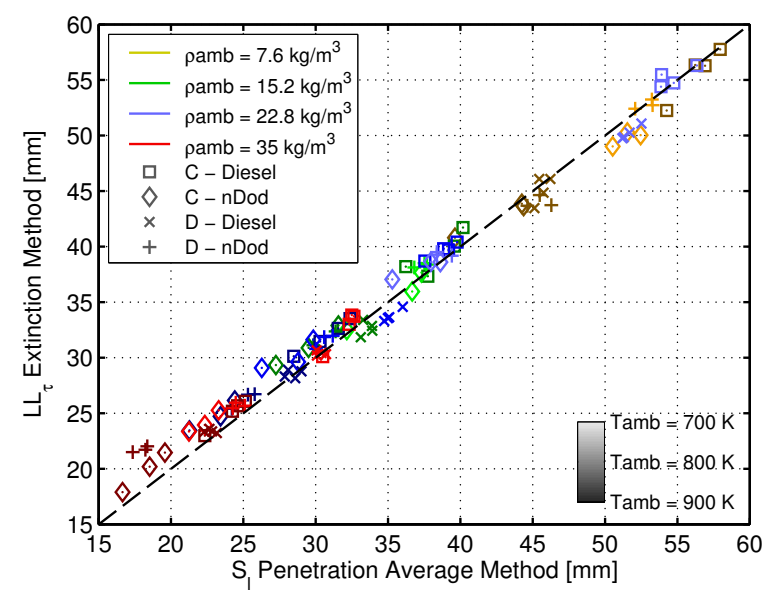

Fig. 13: Liquid length results for all tests. Horizontal axis correspond to $\overline{S_{l}}$ obtained by averaging the stabilized liquid penetration, while vertical to $L L_{\tau}$ calculated by the extinction method explained in previous section of the paper. Black dashed line represents $L L_{\tau}=\overline{S_{l}}$.

- Vapor and liquid penetrations and spray angle followed tendencies in accordance with literature respect to conditions variations as chamber temperature, gas density and injection pressure. Ambient temperature promoted the evaporation and mixing processes with negligible influence in inert vapor development. Density affects the aerodynamic interaction between the spray and the ambient and also enhances the mixing and incrementing the spreading angle. Injection pressure increases spray momentum and promotes turbulence.

- R-parameter demonstrated to be a useful concept to characterize penetration and to interestingly describe the spray evolution. For inert conditions, $R$-parameter shows to be generally constant in time for the developed region of the spray, allowing to obtain a unique value $\bar{R}$, independent of time and of the previous advancement of penetration. This value followed the expected behaviors for penetration with injection condition and nozzle-fuel variations.

- The viscosity of each fuel played a notable role in the behavior of all calculated parameters, affecting them differently depending on the nozzle employed. For the conical Spray D nozzle, Reynolds number (higher for the less viscous fuel at same other conditions) increased the velocity and how far could penetration get. In contrast, for Spray $\mathrm{C}$ nozzle, $R e$ and vapor pressures promoted the cavitating regime which, due to the faster liquid breakup, higher spreading angle and reduction in effective diameter that are produced; resulted in a limitation of the spray growth in both liquid and vapor phases. This increment in spray angle with cavitation was highly reflected in angle measurements, which also demonstrated to be greater for the less dense and viscous fuel.

- Pseudo-stable liquid length was calculated through two methodologies: by obtaining the value of the spray axial distance where the linear fit of the drop of the optical thickness between the average and the background images is equal to zero $\left(L L_{\tau}\right)$; and by robustly averaging the liquid penetration in a window of time. Both approaches showed to suitably match with slight differences for low liquid length values. Besides the operation conditions, liquid length is strongly influenced by fuel volatility.

\section{Acknowledgments}

This work was supported by "Ministerio de Economía y Competitividad" of the Spanish Government in the frame of the projects "Estudio de la interacción chorro-pared en condiciones realistas de motor", Ref. TRA2015-67679c2-1-R. Moreover, the optical equipment employed in the project was purchased with investment from Ministerio de Economía y Competitividad FEDER-ICTS-2012-06.

The authors would finally like to thank Borja Hurtado and Alberto Viera for their collaboration in the setup of the experiments and laboratory work. 


\section{References}

[1] M. Costa, U. Sorge, L. Allocca, Increasing energy efficiency of a gasoline direct injection engine through optimal synchronization of single or double injection strategies, Energy Conversion and Management 60 (2012) 77-86. doi $10.1016 / \mathrm{j}$. enconman .2011.12.025

[2] R. Mobasheri, Z. Peng, S. M. Mirsalim, Analysis the effect of advanced injection strategies on engine performance and pollutant emissions in a heavy duty DI-Diesel engine by CFD modeling, International Journal of Heat and Fluid Flow 33 (2012) 59 - 69. doi $10.1016 / j$. ijheatfluidflow. 2011.10.004

[3] R. Payri, J. M. García-Oliver, M. Bardi, J. Manin, Fuel temperature influence on diesel sprays in inert and reacting conditions, Applied Thermal Engineering 35 (2012) 185-195. doi 10.1016/j. applthermaleng.2011.10.027

[4] C. Gong, M. Jangi, X.-S. Bai, Large eddy simulation of n-dodecane spray combustion in a high pressure combustion vessel, Applied Energy 136 (2014). doi $10.1016 / \mathrm{j}$. apenergy . 2014.09.030.

[5] E. Sher, Handbook of Air Pollution from Internal Combustion Engines: Pollutant Formation and Control, 1998.

[6] J. D. Naber, D. L. Siebers, Effects of gas density and vaporization on penetration and dispersion of diesel sprays, SAE Technical Paper 960034 (1996). doi $10.4271 / 960034$.

[7] F. Payri, R. Payri, M. Bardi, M. Carreres, Engine Combustion Network: Influence of the gas properties on the spray penetration and spreading angle, Experimental Thermal and Fluid Science 53 (2014) 236-243. doi $10.1016 /$ j.expthermflusci.2013.12.014

[8] C. Genzale, R. Reitz, M. Musculus, Effects of spray targeting on mixture development and emissions formation in late-injection low-temperature heavy-duty diesel combustion, Proceedings of the Combustion Institute 32 (2009) 2767-2774. doi $10.1016 / \mathrm{j}$.proci.2008.06.072.

[9] R. S. Baert, P. J. Frijters, B. Somers, C. C. Luijten, W. de Boer, Design and operation of a high pressure, high temperature cell for HD Diesel spray diagnostics: guidelines and results, SAE Technical Paper 2009-04-20 (2009). doi $10.4271 / 2009-01-0649$

[10] M. Bardi, R. Payri, L. M. Malbec, G. Bruneaux, L. M. Pickett, J. Manin, T. Bazyn, C. Genzale, Engine Combustion Network: comparison of spray development, vaporization, and combustion in different combustion vessels, Atomization and Sprays 22 (2012). doi 10 .1615/AtomizSpr . 2013005837.

[11] S. Martínez-Martínez, M. García-Yera, V. Bermudez, Experimental Cells for Research Diesel Sprays, Fuel Injection, InTech, 2010. doi $10.5772 / 9725$

[12] J. V. Pastor, R. Payri, J. M. García-Oliver, J. G. Nerva, Schlieren Measurements of the ECN-Spray A Penetration under Inert and Reacting Conditions, SAE Technical Paper 2012-01-0456 (2012). doi 10.4271/ 2012-01-0456

[13] J. Manin, M. Bardi, L. M. Pickett, Evaluation of the liquid length via diffused back-illumination imaging in vaporizing diesel sprays, in: COMODIA 8th-2012, Fukuoka, Japan. The International Symposium on Diagnostics and Modeling of Combustion In Internal Combustion Engines., 2012.

[14] L. M. Pickett, C. Genzale, J. Manin, L. M. Malbec, L. Hermant, Measurement uncertainty of liquid penetration in evaporating diesel sprays, in: ILASS Americas 2011, 23rd Annual Conference on Liquid Atomization and Spray Systems, Ventura, CA, 2011.

[15] C. Espey, J. E. Dec, The effect of tdc temperature and density on the liquid-phase fuel penetration in a d.i. diesel engine, SAE Technical Paper 952456 (1995). doi $10.4271 / 952456$

[16] D. Siebers, Scaling liquid-phase fuel penetration in diesel sprays based on mixing-limited vaporization, SAE Technical Paper 1999-01-0528 (1999). doi 10 .4271/1999-01-0528. 
[17] R. Payri, J. Gimeno, M. Bardi, A. H. Plazas, Study liquid length penetration results obtained with a direct acting piezo electric injector, Applied Energy 106 (2013) 152-162. doi $10.1016 / \mathrm{j}$. apenergy 2013. 01.027

[18] D. Siebers, Liquid-phase fuel penetration in Diesel sprays, SAE Technical Paper 980809 (1998). doi 10 . $4271 / 980809$

[19] R. Reitz, F. Bracco, On the dependence of spray angle and other spray parameters on nozzle design and operating conditions, Technical Paper 790494 (1979). doi 10 . $4271 / 790494$

[20] H. Chaves, M. Knapp, A. Kubitzek, F. Obermeier, Experimental study of cavitation in the nozzle hole of diesel injectors using transparent nozzles, SAE Technical Paper 950290 (1995). doi:10 . 4271/950290

[21] H. Hiroyasu, S. M., A. M., Breakup length of a liquid jet and internal flow in a nozzle, in: ICLASS-91, 1991.

[22] R. Payri, F. J. Salvador, J. Gimeno, O. Venegas, Study of cavitation phenomenon using different fuels in a transparent nozzle by hydraulic characterization and visualization, Experimental Thermal and Fluid Science 44 (2013) 235-244. doi $10.1016 /$ j . expthermflusci.2012.06.013

[23] C. Soteriou, M. Smith, R. Andrews, Diesel injection: laser light sheet illumination of the development of cavitation in orifices, in: IMECHE conference transactions, 1998, pp. 137-158.

[24] A. Sou, S. Minami, R. Prasetya, R. Pratama, S. Moon, Y. Wada, H. Yokohata, X-ray visualization of cavitation in nozzles with various sizes, ICLASS-15 (2015).

[25] Z. He, H. Zhong, Q. Wang, Z. Jiang, Z. Shao, Effect of nozzle geometrical and dynamic factors on cavitating and turbulent flow in a diesel multi-hole injector nozzle, International Journal of Thermal Sciences (2013) 132-143. doi $10.1016 /$ j.ijthermalsci.2013.03.008

[26] ECN, Engine Combustion Network, Online, 2015. URL: WwW . sandia.gov/ecn/

[27] A. Kastengren, F. Tilocco, C. Powell, J. Manin, L. M. Pickett, R. Payri, T. Bazyn, Engine Combustion Network (ECN): Measurements of nozzle diameter and hydraulic behavior, Atomization And Sprays 22 (2012) 10111052. doi 10.1615/AtomizSpr. 2013006309

[28] R. Payri, F. J. Salvador, J. Gimeno, J. E. Peraza, Experimental study of the injection conditions influence over n-dodecane and diesel sprays with two ECN single-hole nozzles. Part II: Reacting atmosphere, Energy Conversion and Management (2016).

[29] S. E. Parrish, R. Zink, Development and Application of Imaging System to Evaluate Liquid and Vapor Envelopes of Multi-Hole Gasoline Fuel Injector Sprays under Engine-like Conditions, Atomization and Sprays 22 (2012) 647-661. doi 10.1615/AtomizSpr. 2012006215

[30] R. Payri, J. Gimeno, J. Cuisano, J. Arco, Hydraulic characterization of diesel engine single-hole injectors, Fuel 180 (2016) 357-366. doi $10.1016 / \mathrm{j}$.fuel.2016.03.083

[31] J. Manin, S. Skeen, L. M. Pickett, Measurement of liquid and vapor penetration of diesel sprays with a variation in spreading angle, SAE Technical Paper 2015-01-0946 (2015). doi 10 . 4271/2015-01-0946

[32] G. S. Settles, Schileren and Shadowgraph Techniques., Springer Berlin, 2001. doi 10.1007/ 978-3-642-56640-0

[33] J. M. Desantes, R. Payri, F. Salvador, A. Gil, Development and validation of a theoretical model for diesel spray penetration, Fuel 85 (2006) pp. 910-917. doi $10.1016 / \mathrm{j}$. fuel.2005.10.023

[34] P. Martí-Aldaraví, Development of a Computational Model for a Simultaneous Simulation of Internal Flow and Spray Break-up of the Diesel Injection Process, Ph.D. thesis, Universitat Politecnica de Valencia. Departamento de Maquinas y Motores Termicos., 2014. doi 10.4995/Thesis/10251/43719.

[35] R. Payri, J. Gimeno, J. P. Viera, A. H. Plazas, Needle lift profile influence on the vapor phase penetration for a prototype diesel direct acting piezoelectric injector., Fuel 113 (2013) 257-265. doi 10 . 1016/j . fuel . 2013.05 .057 
[36] R. Perry, D. Green, Perry's Chemical Engineers' Handbook, McGraw-Hill, ISBN 978-0-07-049841-9., 1997.

[37] F. J. Salvador, J. Martínez-López, C. Caballer, M.and De Alfonso, Study of the influence of the needle lift on the internal flow and cavitation phenomenon in diesel injector nozzles by cfd using rans methods, Energy Conversion and Management 66 (2013) 246-256. doi 10.1016/j . enconman.2012 .10.011 